\title{
Rare gastric outlet obstruction owing to ectopic pancreas: a case report and literature review
}

\author{
Kunihiko Yokoyama $^{1,2}$, Hiroki Sato ${ }^{2}$, Yuichi Sato ${ }^{1}$, Jun Watanabe ${ }^{1}$, Atsuo Nakamura ${ }^{1}$, Shuji Terai $^{2}$ \\ ${ }^{1}$ Division of Gastroenterology and Hepatology, Niigata prefectural Yoshida Hospital, Niigata, Japan; ${ }^{2}$ Division of Gastroenterology and Hepatology, \\ Niigata University Medical and Dental Hospital, Niigata, Japan \\ Correspondence to: Hiroki Sato, MD, PhD. Division of Gastroenterology, Niigata University Medical and Dental Hospital, 757-1, Asahimachidori, \\ Chuo-ku, Niigata City, Niigata 951-8510, Japan. Email: pyloki-sato@med.niigata-u.ac.jp.
}

\begin{abstract}
The ectopic pancreas is often observed in the gastrointestinal tract, and is typically asymptomatic. A 28-year-old woman was referred to our hospital following repeated vomiting after every meal. Following gastroscopy, contrast-enhanced computed tomography (CE-CT), and endoscopic ultrasonography (EUS), she was diagnosed with gastric outlet obstruction, also known as pyloric obstruction, caused by a giant submucosal cystic tumor. The condition was successfully treated with EUS-guided cystic drainage, and she was diagnosed with a cystic tumor originating from the ectopic pancreas. The tumor shrank following EUSguided cystic drainage, and her obstructive symptoms resolved. In cases with overgrowth of the ectopic pancreas, the differential diagnosis of malignancy is important but challenging. Herein, we report a unique final pathology of this rare case and discuss the findings with a literature review.
\end{abstract}

Keywords: Case report; gastric outlet obstruction, endoscopic ultrasonography (EUS); ectopic pancreas

Submitted Nov 01, 2019. Accepted for publication Dec 27, 2019.

doi: 10.21037/atm.2020.01.64

View this article at: http://dx.doi.org/10.21037/atm.2020.01.64

\section{Introduction}

The ectopic pancreas is a congenital anomaly in which the pancreatic tissue is located outside its normal anatomical location and lacks vascular or ductal continuity. The ectopic pancreas is often visible in various organs, including the gastrointestinal tract, and is typically asymptomatic (1). In this report, we describe a rare case of cystic tumor involving the ectopic pancreas, which caused the gastric outlet obstruction, also known as pyloric obstruction. Final pathology results were obtained, and the unique histology is discussed with a literature review.

\section{Case presentation}

A 28-year-old woman with no remarkable medical or family history was referred to our hospital following complaints of repeated vomiting after every meal for 3 months. Physical examination and laboratory tests revealed no specific findings. Gastroscopy revealed a giant submucosal tumor
(SMT) in the gastric antrum, obstructing the pyloric ring (Figure 1). Contrast-enhanced computed tomography (CE-CT) revealed a cystic tumor with a diameter of $5.8 \mathrm{~cm}$; furthermore, the septal wall was minimally enhanced (Figure 2). SMT was solitary, and no other lesions were detected in the duodenum as well.

Endoscopic ultrasonography (EUS) was performed. The first and second layer corresponding to mucosa was intact and a large cystic lesion originating from the third layer corresponded to the submucosal growth. Subsequently, EUS-guided fine cyst drainage (EUS-CD) was successfully performed (Figure 3), and a total of $30 \mathrm{~mL}$ of internal serous liquid was aspirated (Figure 3 inset). There were no procedural adverse events. The amylase level in the fluid was elevated at 9,623 U/L; therefore, the gastric ectopic pancreas was diagnosed. The tumor shrank following EUS$\mathrm{CD}$, and her obstructive symptoms resolved.

Thereafter, laparoscopic surgical resection was performed to achieve a histological diagnosis and prevent recurrence 
Page 2 of 6

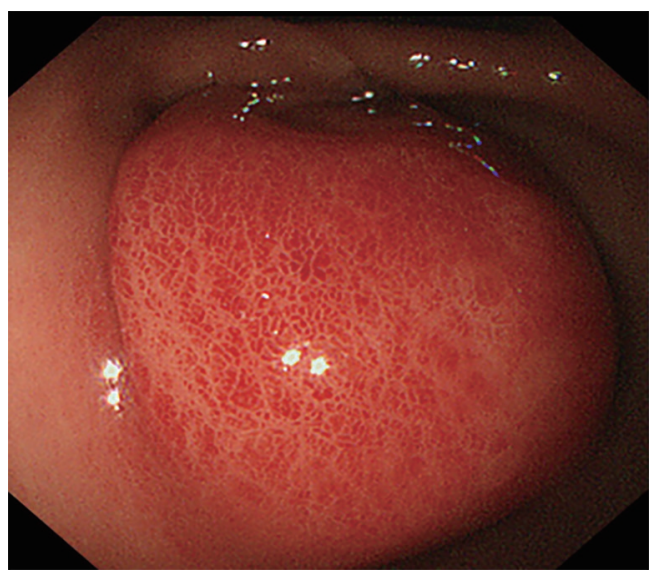

Figure 1 Gastroscopy image revealing a giant submucosal tumor obstructing the pyloric ring.

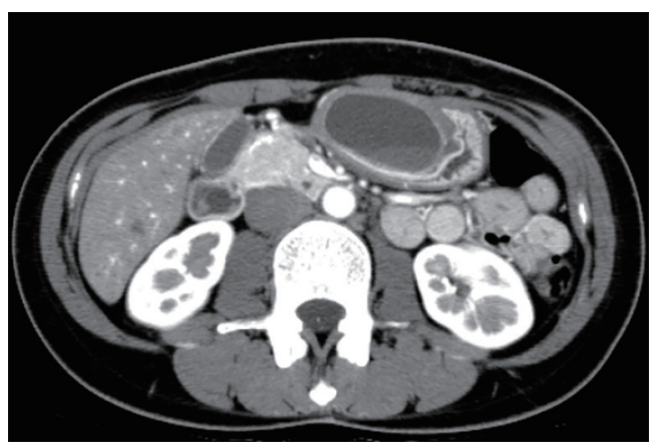

Figure 2 Contrast-enhanced computed tomography scan showing a cystic tumor with a diameter of $5.8 \mathrm{~cm}$, with minimal enhancement of the septal wall.

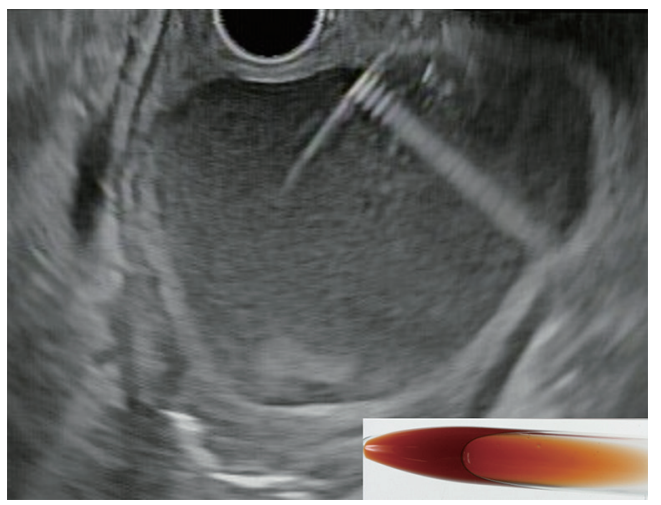

Figure 3 Endoscopic ultrasonography-guided fine cyst drainage successfully performed and aspiration of serous fluid with high amylase levels (inset).

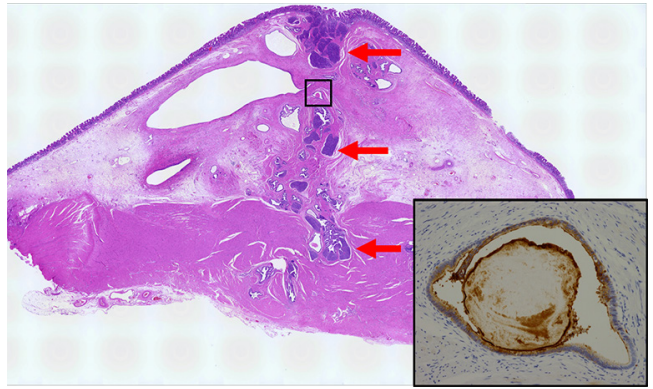

Figure 4 The resected specimen showing a pseudocyst on the ectopic pancreas. The heterotopic pancreas is characterized by a large number of ducts and acini (red arrows). The area of the black box is magnified in the inset (CEA staining, $\times 400$ magnification).

upon the patient's request. On final pathology, a pseudocyst was detected on the ectopic pancreas. The ectopic pancreas had a microscopic appearance consistent with Heinrich's class II pancreatic tissue (1), with the majority of the heterotopic pancreas characterized by a large number of ducts and acini (Figure 4, red arrow). The involvement of the islets of Langerhans was not noted. Malignant components were not observed in the specimen. During one year of follow-up using gastroscopy, no recurrence was observed. Written informed consent was obtained from the patient.

\section{Discussion}

In this report, we describe a rare case of a giant submucosal cystic tumor originating from the ectopic pancreas that was successfully treated by EUS-guided cystic drainage and present the final pathology of this rare case.

Ectopic pancreas involving the stomach is most frequently seen in the antrum (2). Therefore, clinically, gastric outlet obstruction can be caused by a large cystic tumor on the ectopic pancreas. Thus, the ectopic pancreas should be considered in the differential diagnosis of pyloric flow obstruction owing to SMTs. Pathologically, cystic tumors on the ectopic pancreas are caused by the external secretion of mucin and the associated inflammation, which can lead to occlusion of the capillary lumen. EUS and, in succession, EUS-CD were reported to be effective for the diagnosis of SMTs, and treatment of symptomatic cases of cystic tumors on the ectopic pancreas $(3,4)$; however, the long-term treatment efficacy remains unknown. 
Furthermore, malignant transformation is rare but may be detected during long-term follow-up (5-9); therefore, periodic examination with EUS or CE-CT is necessary. The indication of surgical resection is a symptomatic condition, and it may be critical particularly in recurrent and malignant cases.

The literature of the ectopic pancreas in the stomach, which had been histologically confirmed, is summarized in Table 1. The presence of a symptomatic or asymptomatic condition is not considered useful to differentiate cases of malignancy. In contrast, EUS has the potential to diagnose malignancy, and enlargement with time, extramural growth with marginal irregularity, and heterogeneous or multilobulated appearance are suggestive but not specific for malignancy. Inflammation owing to acute pancreatitis shows a high echo signal on EUS; therefore, the mass may look heterogeneous. In patients with pancreatitis on the ectopic pancreas, we also need to carefully consider the symptoms and elevation in serum pancreatic enzymes. Cases wherein the entire mass cannot be observed should be dealt with cautiously, and there should be an objective interpretation of the findings by an expert. Depending on the size and depth of invasion of the tumor, endoscopic submucosal dissection may be used as an alternative approach for histological examination and curative treatment $(21,27)$. Another differential diagnosis is the rare entity of gastric and duodenal cystic dystrophy in heterotopic pancreas $(28,29)$, which is a development of multiple cystic changes in heterotopic pancreatic tissues generally in the duodenum, and in original pancreas; chronic pancreatitis was observed in the majority of them. However, only case reports and case series are available in literature, thereby lacking comparative studies to assess the efficacy of diagnosis and treatment methods, which can be considered a limitation of this study.

In conclusion, the ectopic pancreas should be considered in the differential diagnosis of gastric outlet obstruction. EUS and EUS-CD are effective for the diagnosis and treatment of symptomatic cases, although the indication of surgical resection should be considered according to individual cases.

Table 1 Summary of cases of ectopic pancreas in the stomach confirmed histologically

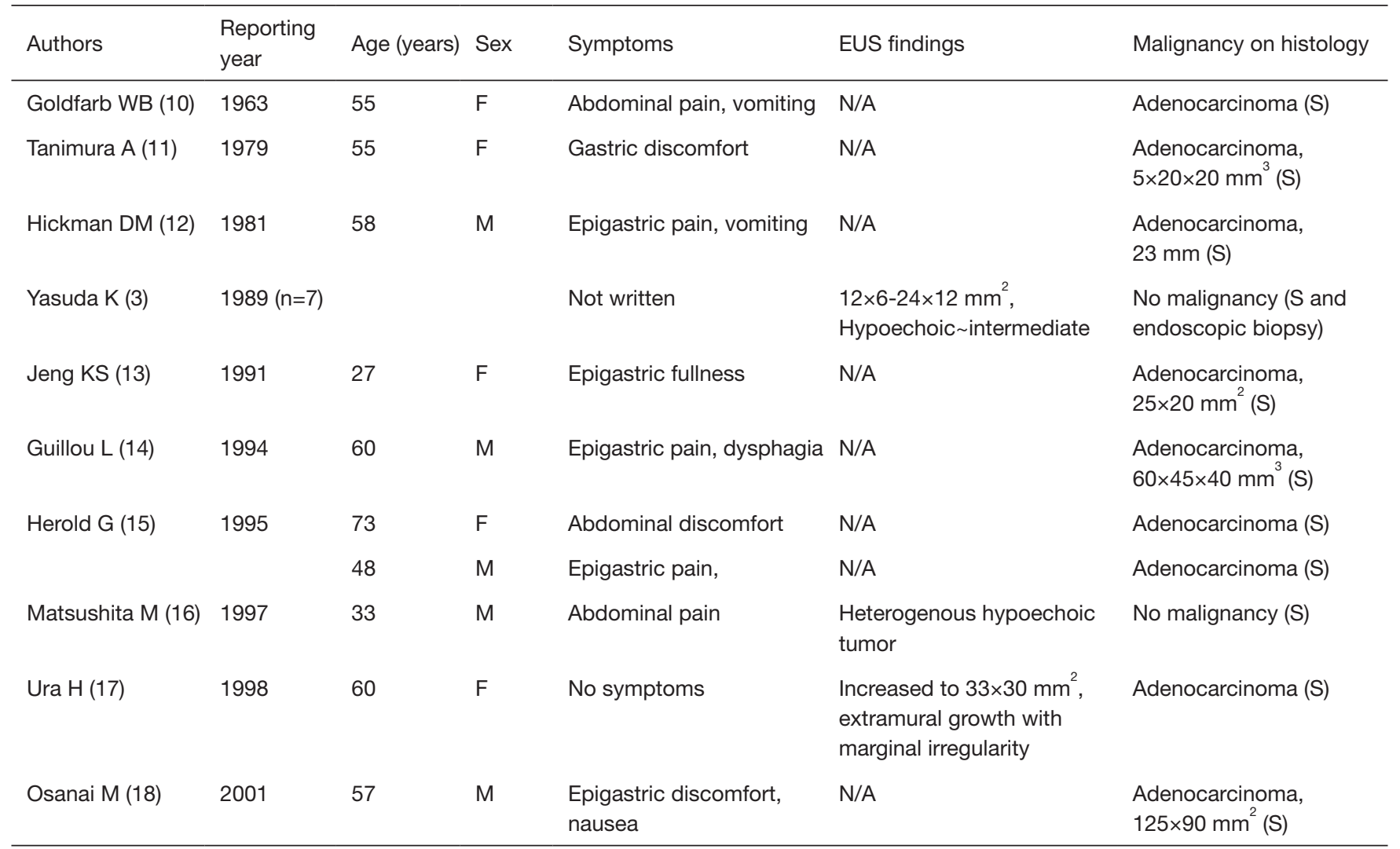

Table 1 (continued) 
Table 1 (continued)

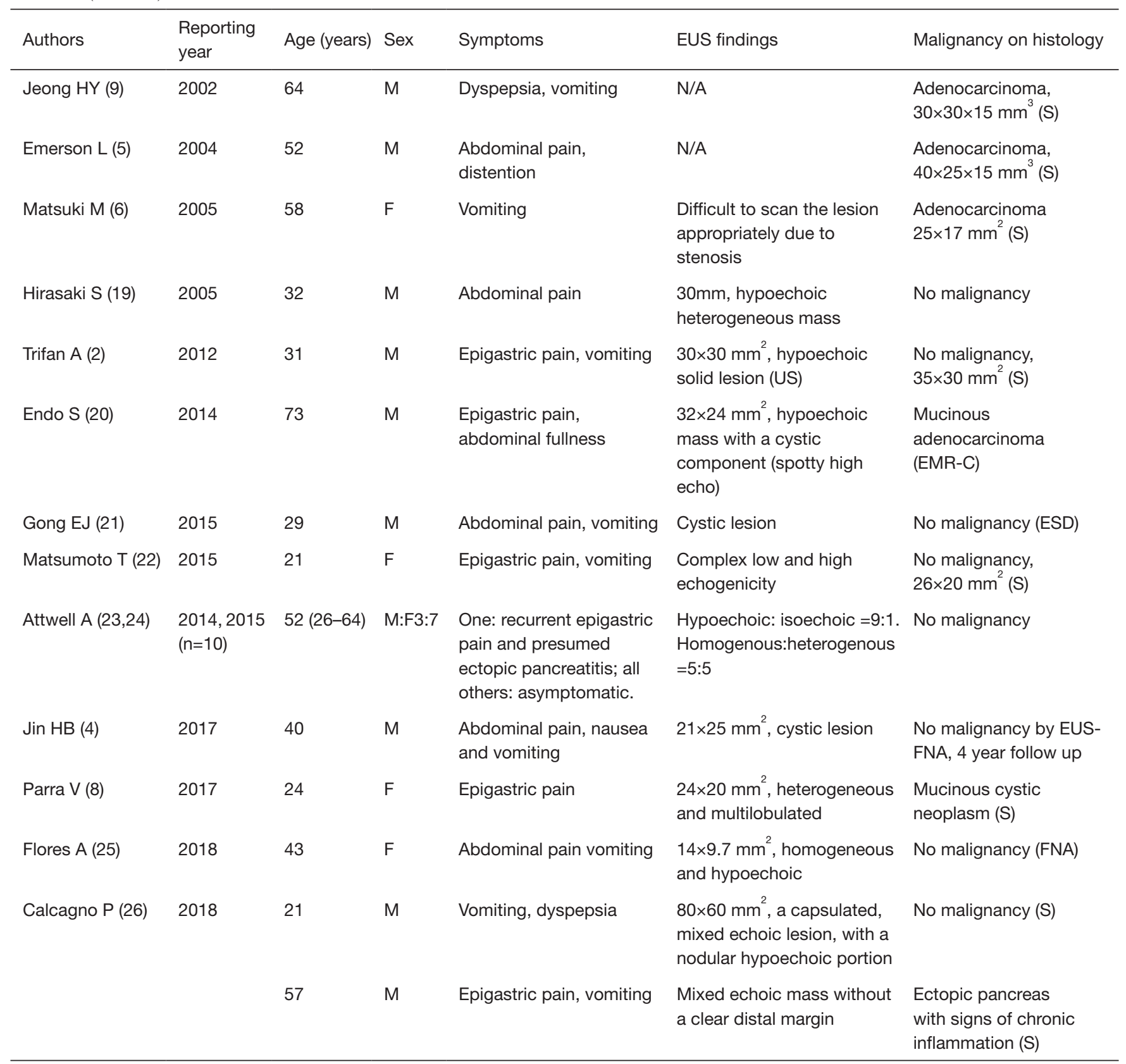

M, Male; F, Female; S, surgical resection; EUS, endoscopic ultrasonography; N/A, not available; FNA, fine needle aspiration; EMR-C, endoscopic mucosal resection-using a Cap fitted endoscope; ESD, endoscopic submucosal dissection.

\section{Acknowledgments}

Funding: None.

\section{Footnote}

Conflicts of Interest: The authors have no conflicts of interest 
to declare.

Ethical Statement: The authors are accountable for all aspects of the work in ensuring that questions related to the accuracy or integrity of any part of the work are appropriately investigated and resolved. Written informed consent was obtained from the patient for publication of this manuscript and any accompanying images.

Open Access Statement: This is an Open Access article distributed in accordance with the Creative Commons Attribution-NonCommercial-NoDerivs 4.0 International License (CC BY-NC-ND 4.0), which permits the noncommercial replication and distribution of the article with the strict proviso that no changes or edits are made and the original work is properly cited (including links to both the formal publication through the relevant DOI and the license). See: https://creativecommons.org/licenses/by-nc-nd/4.0/.

\section{References}

1. Rezvani M, Menias C, Sandrasegaran K, et al. Heterotopic Pancreas: Histopathologic Features, Imaging Findings, and Complications. Radiographics 2017;37:484-99.

2. Trifan A, Tarcoveanu E, Danciu M, et al. Gastric heterotopic pancreas: an unusual case and review of the literature. J Gastrointestin Liver Dis 2012;21:209-12.

3. Yasuda K, Nakajima M, Yoshida S, et al. The diagnosis of submucosal tumors of the stomach by endoscopic ultrasonography. Gastrointest Endosc 1989;35:10-5.

4. Jin HB, Lu L, Yang JF, et al. Interventional endoscopic ultrasound for a symptomatic pseudocyst secondary to gastric heterotopic pancreas. World J Gastroenterol 2017;23:6365-70.

5. Emerson L, Layfield LJ, Rohr LR, et al. Adenocarcinoma arising in association with gastric heterotopic pancreas: A case report and review of the literature. J Surg Oncol 2004;87:53-7.

6. Matsuki M, Gouda Y, Ando T, et al. Adenocarcinoma arising from aberrant pancreas in the stomach. J Gastroenterol 2005;40:652-6.

7. Inoue $Y$, Hayashi $M$, Arisaka $Y$, et al. Adenocarcinoma arising in a heterotopic pancreas (Heinrich type III): a case report. J Med Case Rep 2010;4:39.

8. Parra V, Acero F, Alvarez E, et al. A case of mucinous cystic neoplasm from a gastric ectopic pancreas. Gastrointest Endosc 2017;85:1096-7.
9. Jeong HY, Yang HW, Seo SW, et al. Adenocarcinoma arising from an ectopic pancreas in the stomach. Endoscopy 2002;34:1014-7.

10. Goldfarb WB, Bennett D, Monafo W. Carcinoma in Heterotopic Gastric Pancreas. Ann Surg 1963;158:56-8.

11. Tanimura A, Yamamoto H, Shibata H, et al. Carcinoma in heterotopic gastric pancreas. Acta Pathol Jpn 1979;29:251-7.

12. Hickman DM, Frey CF, Carson JW. Adenocarcinoma arising in gastric heterotopic pancreas. West $\mathrm{J}$ Med 1981;135:57-62.

13. Jeng KS, Yang KC, Kuo SH. Malignant degeneration of heterotopic pancreas. Gastrointest Endosc 1991;37:196-8.

14. Guillou L, Nordback P, Gerber C, et al. Ductal adenocarcinoma arising in a heterotopic pancreas situated in a hiatal hernia. Arch Pathol Lab Med 1994;118:568-71.

15. Herold G, Kraft K. Adenocarcinoma arising from ectopic gastric pancreas: two case reports with a review of the literature. Z Gastroenterol 1995;33:260-4.

16. Matsushita M, Hajiro K, Takakuwa H. Acute pancreatitis occurring in gastric aberrant pancreas accompanied by paralytic ileus. Am J Gastroenterol 1997;92:2121-2.

17. Ura H, Denno R, Hirata K, et al. Carcinoma arising from ectopic pancreas in the stomach: endosonographic detection of malignant change. J Clin Ultrasound 1998;26:265-8.

18. Osanai M, Miyokawa N, Tamaki T, et al. Adenocarcinoma arising in gastric heterotopic pancreas: clinicopathological and immunohistochemical study with genetic analysis of a case. Pathol Int 2001;51:549-54.

19. Hirasaki S, Tanimizu M, Moriwaki T, et al. Acute pancreatitis occurring in gastric aberrant pancreas treated with surgery and proved by histological examination. Intern Med 2005;44:1169-73.

20. Endo S, Saito R, Ochi D, et al. Effectiveness of an endoscopic biopsy procedure using EUS-FNA and EMR-C for diagnosing adenocarcinoma arising from ectopic pancreas: two case reports and a literature review. Intern Med 2014;53:1055-62.

21. Gong EJ, Kim DH, Cho CJ, et al. Endoscopic submucosal dissection of ectopic pancreas with pancreatitis and pseudocyst formation. Gastrointest Endosc 2015;82:1126.

22. Matsumoto T, Tanaka N, Nagai M, et al. A case of gastric heterotopic pancreatitis resected by laparoscopic surgery. Int Surg 2015;100:678-82.

23. Attwell A, Sams S, Fukami N. Induction of acute ectopic pancreatitis by endoscopic ultrasound with fine-needle 
aspiration. Clin Gastroenterol Hepatol 2014;12:1196-8.

24. Attwell A, Sams S, Fukami N. Diagnosis of ectopic pancreas by endoscopic ultrasound with fine-needle aspiration. World J Gastroenterol 2015;21:2367-73.

25. Flores A, Papafragkakis C, Uberoi AS, et al. EUS of an atypical ectopic pancreas. Endosc Ultrasound 2018;7:216-7.

26. Calcagno P, Lotti M, Campanati L, et al. Emergency Presentation of Gastric Ectopic Pancreas. Cureus 2018;10:e3565.

Cite this article as: Yokoyama K, Sato H, Sato Y, Watanabe J, Nakamura A, Terai S. Rare gastric outlet obstruction owing to ectopic pancreas: a case report and literature review. Ann Transl Med 2020;8(5):252. doi: 10.21037/atm.2020.01.64
27. Ning X, Liang B, Liu Q, et al. Gastric inflammatory myofibroblastic tumor identified as ectopic pancreas and treated by endoscopic submucosal dissection. Gastrointest Endosc 2017;86:921-2.

28. Fléjou JF, Potet F, Molas G, et al. Cystic dystrophy of the gastric and duodenal wall developing in heterotopic pancreas: an unrecognised entity. Gut 1993;34:343-7.

29. Rebours V, Levy P, Vullierme MP, et al. Clinical and morphological features of duodenal cystic dystrophy in heterotopic pancreas. Am J Gastroenterol 2007;102:871-9. 